\title{
A radiolucent lesion of the jaw as a presentation form of a mucoepidermoid carcinoma of the oral cavity
}

\author{
David A. Dominguez-Medina ${ }^{1}$, Juan F. Peña-Cardelles², Felix Manzarbeitia-Arambarri ${ }^{3}$ \\ ${ }^{1}$ Unit of Oral and Maxillofacial Surgery and Odontology, Hospital La Luz, ${ }^{2}$ Faculty of Dentistry, Rey Juan Carlos University, \\ ${ }^{3}$ Department of Pathology, Fundacion Jimenez Diaz University Hospital, Madrid, Spain
}

\begin{abstract}
J Korean Assoc Oral Maxillofac Surg 2021;47:229-232)
Cancer of the oral cavity and pharynx represents the 7th most diagnosed malignancy in Spain. Mucoepidermoid carcinomas are the most frequent malignancies of the minor salivary glands of oral cavities. The purpose of this report is to describe the very rare case of an alveolar ridge high-grade mucoepidermoid carcinoma presenting as an inside socket radiolucent lesion, simulating an apical cyst. The patient was diagnosed in our unit for oral and maxillofacial surgery and treated with surgery and adjuvant radiotherapy. The patient continues to be free of recurrent/persistent, local/regional disease after two years of follow up. Non-healed tooth related lesions present for more than one year are strongly recommended to be biopsied and evaluated histopathologically.
\end{abstract}

Key words: Oral cavity, Mucoepidermoid carcinoma, Radiolucent lesion

[paper submitted 2019. 11. 14 / accepted 2020. 1. 28]

\section{Introduction}

Cancer of the oral cavity and pharynx is the seventh most diagnosed cancer in Spain with an estimated 8,486 new cases in $2019^{1}$. Mucoepidermoid carcinomas are the most common malignancies of intraoral minor salivary glands, ranging from $22 \%$ to $44 \%$ of cases $^{2}$.

The most frequent location of mucoepidermoid carcinomas is the palate, and can rarely present in the jaw as intraosseous tumors, referred to as central mucoepidermoid carcinomas ${ }^{3}$.

Due to a tumor's ability to produce mucin and form cystic spaces, their presentation can resemble ranulas, mucoceles ${ }^{3}$, or even radiolucent bone lesions ${ }^{2}$.

Among teeth-associated radiolucent lesions, $73 \%$ are classified as apical granulomas, cysts or abscesses and 3\% ac-

\section{David A. Dominguez-Medina}

Unit of Oral and Maxillofacial Surgery and Odontology, Hospital La Luz, Calle de la Cueva de Montesinos \# 94, Ground Floor, Madrid 28034, Spain TEL: +34-622915286

E-mail: dominguez.medina.david@gmail.com

ORCID: https://orcid.org/0000-0001-5426-8270

(c) This is an open-access article distributed under the terms of the Creative Commons Attribution Non-Commercial License (http://creativecommons.org/ licenses/by-nc/4.0/), which permits unrestricted non-commercial use, distribution, and reproduction in any medium, provided the original work is properly cited.

Copyright (C) 2021 The Korean Association of Oral and Maxillofacial Surgeons. All rights reserved. count for malignancies ${ }^{4}$.

The objective of this report is to present an unusual case of a mucoepidermoid carcinoma masked as a non-healed radiotransparent jaw lesion associated with an endodontic tooth, where clinical findings pointed to a benign condition.

\section{Case Report}

A 54-year-old female was referred to our unit with the chief complaint of one month's occasional pain from the inferior left first molar and a painless bulge on its gums present for one year. Her relevant past medical history was a successfully treated breast carcinoma ( $1 \mathrm{cN} 1 \mathrm{bM} 0)$ and autoimmune hepatitis.

Intraoral examination revealed a discrete, non-fluctuant, vestibular bulge in the gums adjacent to tooth 3.6, which was previously restored with a crown. Tooth vitality was negative although it was sensitive to percussion.

Initial panoramic X-ray showed tooth 3.6 was endodontically treated and presented with a well-defined radiolucent lesion of approximately $15 \mathrm{~mm}$ in diameter occupying the socket (Fig. 1), while a 4-year prior X-ray confirmed the lesion was already present but significantly smaller $(2 \mathrm{~mm})$. The computed tomography scan revealed a defined soft tissue-density lesion occupying the tooth socket and an external 


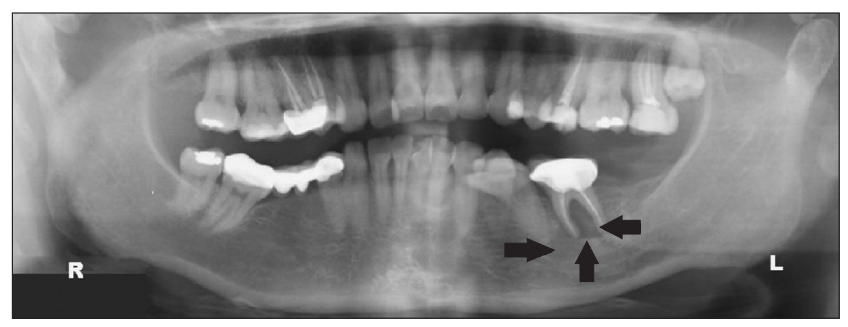

Fig. 1. Initial panoramic $X$-ray showing the radiolucent lesion (arrows) occupying the entire socket of mandibular left first molar. David A. Dominguez-Medina et al: A radiolucent lesion of the jaw as a presentation form of a mucoepidermoid carcinoma of the oral cavity. J Korean Assoc Oral Maxillofac Surg 2021

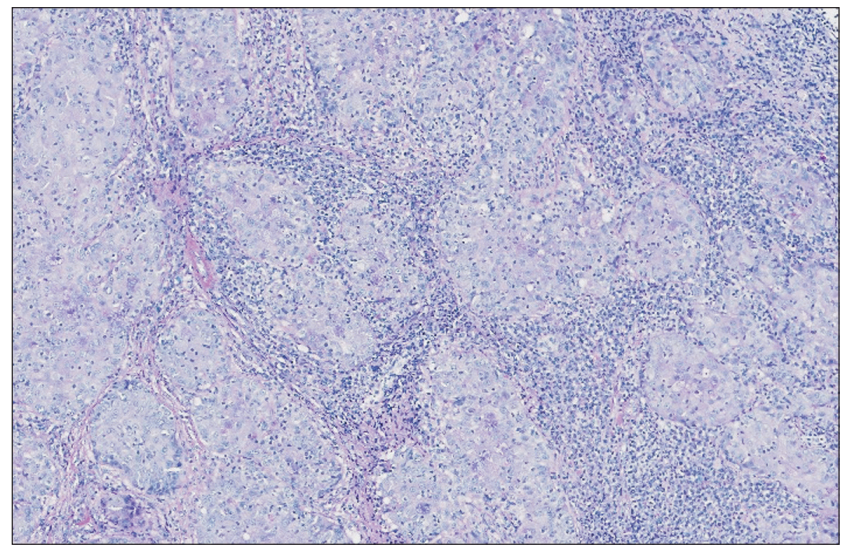

Fig. 2. H\&E staining $(x 1)$ photomicrograph showing the neoplasia forming solid nests, separated by fibroinflammatory stroma.

David A. Dominguez-Medina et al: A radiolucent lesion of the jaw as a presentation form of a mucoepidermoid carcinoma of the oral cavity. J Korean Assoc Oral Maxillofac Surg 2021

cortical bone defect.

The plan proposed at that time was tooth extraction with curettage of the socket. It was expected to restore the zone with a differed unitary dental implant. During the procedure, the lesion was easily excised, fat-like in consistency, and did not seem to invade the bone.

Histopathological evaluation showed a tumor forming solid nests of epidermoid cells principally.(Fig. 2) Given the patient's oncologic background, immunohistochemical analysis was performed, confirming the tumor's squamous origin and dismissing mammary origin.(Fig. 3) The findings were compatible with a high-grade mucoepidermoid carcinoma.

This unexpected diagnose required modification of the treatment plan. Physical exploration of the neck did not reveal any existing palpable lymph nodes. A neck magnetic resonance imaging (MRI) and positron emission tomography (PET) scan were urgently scheduled as extension studies. MRI revealed few submandibular left lymph nodes that were not clearly suspicious. PET scan revealed a focal pathologic

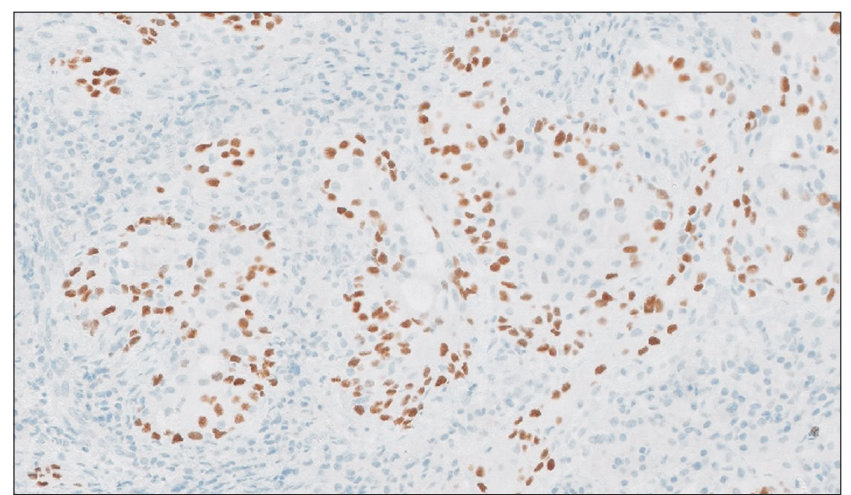

Fig. 3. Photomicrograph of the immunohistochemical analysis $(x 1)$ for P40 whose positivity in the nuclei confirmed the squamousrelated origin of the tumor.

David A. Dominguez-Medina et al: A radiolucent lesion of the jaw as a presentation form of a mucoepidermoid carcinoma of the oral cavity. J Korean Assoc Oral Maxillofac Surg 2021

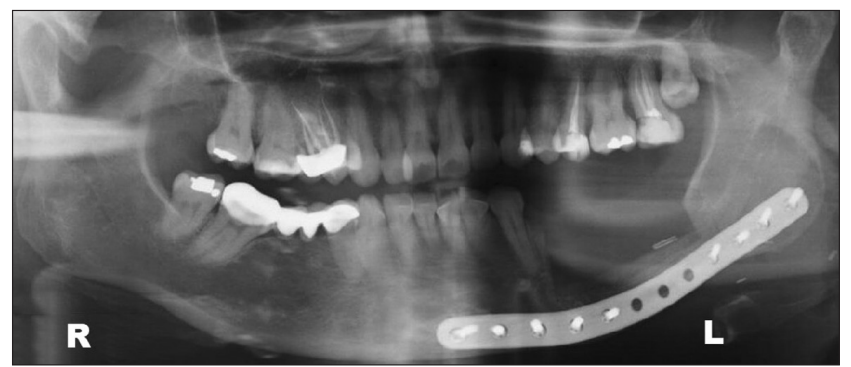

Fig. 4. Postsurgery panoramic $X$-ray showing the amplitude of the bone resection and the choice of reinforcement using a 2.0 reconstruction plate at the basal margin.

David A. Dominguez-Medina et al: A radiolucent lesion of the jaw as a presentation form of a mucoepidermoid carcinoma of the oral cavity. J Korean Assoc Oral Maxillofac Surg 2021

deposit in the zone containing the healing socket. Macroscopic active distant disease was dismissed.

It was explained to the patient that she needed more significant surgery. The resection was outlined in the alveolar ridge soft tissue around the healing socket with a $1 \mathrm{~cm}$ margin along with a marginal mandibular body resection. Left supraomohyoid neck dissection was performed. A titanium preformed reconstruction plate (2.0 profile) was placed at the basal mandibular margin to reinforce the segment.(Fig. 4) Intraoral soft tissue defect was achieved using a combination of local vestibular flaps.

Final histopathological analysis revealed an infiltrating high-grade mucoepidermoid carcinoma with $0.4 \mathrm{~cm}$ maximum thickness. The tumor was not present within the bone sample. In the neck dissection sample, there was $1 / 23$ intracapsular metastasis.(Fig. 5) No perineural invasion was found.

Final staging was T2N1M0. The patient was referred for 


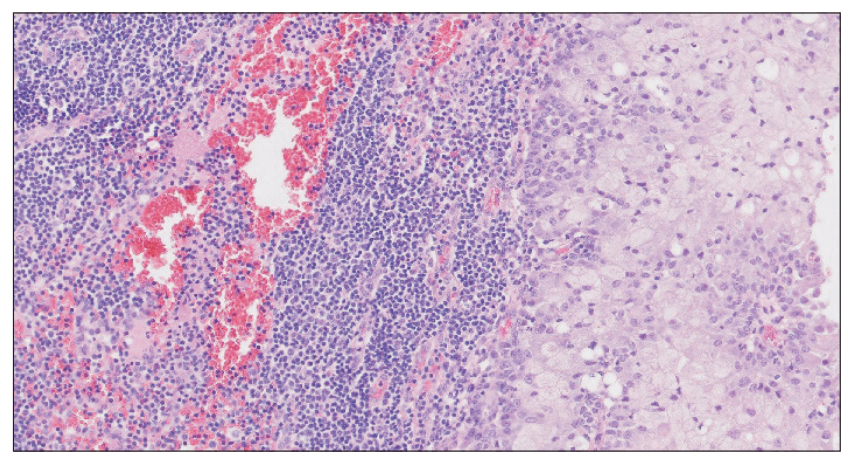

Fig. 5. Photomicrograph of the unitary lymph node metastasis (H\&E staining, $\times 20)$.

David A. Dominguez-Medina et al: A radiolucent lesion of the jaw as a presentation form of a mucoepidermoid carcinoma of the oral cavity. J Korean Assoc Oral Maxillofac Surg 2021

evaluation to a medical and radiation oncologist. Adjuvant radiotherapy (intensity-modulated radiation therapy) was conducted two months after surgery, and the total dose for the surgical zone and neck was 64 Gy. The duration of therapy was one and a half months. Correct follow-up was made by both the oncologist and surgical team, and the patient has remained free of new, persistent, or recurrent disease for the last two years.

\section{Discussion}

Most reported mucoepidermoid carcinomas simulated lesions that involved only soft tissues ${ }^{3}$. Our report is the first where the carcinoma may have emerged from a non-healed apical granuloma, as the main lesion was located inside the tooth socket and directly related to the endodontically treated tooth.

Cystic lesion simulating malignancies can appear as either regular or irregular radiolucent lesions, and can exhibit a mixed pattern of radiolucency, such as with clear cell odontogenic carcinoma ${ }^{5}$.

The most frequent clinics for mucoepidermoid carcinomas remain asymptomatic, although the most reported symptom was dull pain ${ }^{2}$. This is consistent with our case, which was only occasionally painful at the end. This behavior should be acknowledged by all clinicians so that non-healed jaw lesions present for more than one year should be biopsied for pathologic evaluation.

Note that PET scan is not helpful in distinguishing benign from malignant lesions ${ }^{3}$, and therefore the meaning of increased metabolic uptake should be considered carefully, especially when a recent surgery background is present, largely indicating the presence of inflammatory changes in the area.

Tumor grading has prognostic value and is essential for choosing appropriate treatment ${ }^{2}$. Our report on an infiltrating high-grade tumor treated with surgery and radiotherapy is consistent with achieving good local control; however, this malignancy appears to be radioresistant ${ }^{6}$.

Expression of Ki-67 antigen is correlated with increased histological grade, as it was found in $10 \%$ of high grade tumors. Although immunohystochemical analysis is not performed systematically to the samples; however, we should keep in mind that in high-grade tumors, with the presence of this marker, it is possible to provide additional prognostic information related to the tumor's biological behaviour ${ }^{6}$. In our report, immunohistochemical evaluation was helpful to confirm the epidermoid origin of the tumor, clarifying that the tumor was not related with the previous breast tumor.

Although most studies agree that tumor size is the most important predictive factor for survival, both the $\mathrm{T}$ stage and $\mathrm{N}$ stage are significant survival predictive parameters and are more powerful than the histologic subtype ${ }^{7}$. Only one study reported that the $\mathrm{N}$ stage was not a significant predictor for survival, but it was a predictor for tumor local control ${ }^{8}$. Perineural invasion was both a negative survival predictor and a treatment failure predictor when a major nerve was involved".

It is important to relate clinical features (e.g., length of time the tumor has been present) together with both histological features (e.g., pattern of invasion) and surgery-related features (e.g., the presence of positive margins and perineural invasion), as all of these features are directly associated with the clinical course, aggressiveness, and worse prognosis ${ }^{10}$.

\section{ORCID}

David A. Dominguez-Medina, https://orcid.org/0000-00015426-8270

Juan F. Peña-Cardelles, https://orcid.org/0000-0002-78710251

Felix Manzarbeitia-Arambarri, https://orcid.org/0000-00021983-6575

\section{Authors' Contributions}

D.A.D.M. contributed with case selection and manuscript writing. J.F.P.C. contributed with article's research. F.M.A. contributed with the case samples' hystopathologic analysis and provided the case photomicrographies. 


\section{Conflict of Interest}

No potential conflict of interest relevant to this article was reported.

\section{References}

1. Las cifras del cáncer en España [Internet]. Madrid: Sociedad Española de Oncología Médica (SEOM) [cited 2019 May 13]. Available from: https://seom.org/dmcancer/wp-content/uploads/2019/ informe-SEOM-cifras-cancer-2019.pdf

2. Trattner BA, Barak Y, Tordik PA. Mucoepidermoid carcinoma mimicking a lesion of endodontic origin. J Endod 2018;44:1303-7. https://doi.org/10.1016/j.joen.2018.04.018

3. Sousa Melo SL, Lanzel E, Pagedar NA, Alhazmi D, Dahmoush L, Policeni BA, et al. Mucoepidermoid carcinoma mimicking a mucocele (ranula) in the floor of the mouth. Dentomaxillofac Radiol 2018;47:20170331. https://doi.org/10.1259/dmfr.20170331

4. Koivisto T, Bowles WR, Rohrer M. Frequency and distribution of radiolucent jaw lesions: a retrospective analysis of 9,723 cases. $\mathrm{J}$ Endod 2012;38:729-32. https://doi.org/10.1016/j.joen.2012.02.028

5. Kim M, Cho E, Kim JY, Kim HS, Nam W. Clear cell odontogenic carcinoma mimicking a cystic lesion: a case of misdiagnosis. J Korean Assoc Oral Maxillofac Surg 2014;40:199-203. https://oi. org/10.5125/jkaoms.2014.40.4.199

6. Triantafillidou K, Dimitrakopoulos J, Iordanidis F, Koufogiannis D. Mucoepidermoid carcinoma of minor salivary glands: a clinical study of 16 cases and review of the literature. Oral Dis 2006;12:364-70. https://doi.org/10.1111/j.1601-0825.2005.01166.x

7. Kakarala K, Bhattacharyya N. Survival in oral cavity minor salivary gland carcinoma. Otolaryngol Head Neck Surg 2010;143:1226. https://doi.org/10.1016/j.otohns.2010.02.033

8. Parsons JT, Mendenhall WM, Stringer SP, Cassisi NJ, Million RR. Management of minor salivary gland carcinomas. Int J Radiat Oncol Biol Phys 1996;35:443-54. https://doi.org/10.1016/s03603016(96)80005-8

9. Garden AS, Weber RS, Ang KK, Morrison WH, Matre J, Peters LJ. Postoperative radiation therapy for malignant tumors of minor salivary glands. Outcome and patterns of failure. Cancer 1994;73:25639. https://doi.org/10.1002/1097-0142(19940515)73:10<2563::aidcncr2820731018>3.0.co; 2 -x

10. Kolokythas A, Connor S, Kimgsoo D, Fernandes RP, Ord RA. Low-grade mucoepidermoid carcinoma of the intraoral minor salivary glands with cervical metastasis: report of 2 cases and review of the literature. J Oral Maxillofac Surg 2010;68:1396-9. https:// doi.org/10.1016/j.joms.2009.12.019

How to cite this article: Dominguez-Medina DA, Peña-Cardelles JF, Manzarbeitia-Arambarri F. A radiolucent lesion of the jaw as a presentation form of a mucoepidermoid carcinoma of the oral cavity. J Korean Assoc Oral Maxillofac Surg 2021;47:229-232. https://doi.org/10.5125/jkaoms.2021.47.3.229 